\title{
Evaluation of Urban Middle Voltage Distribution Network Reliability Depending on Number of Elements
}

\author{
Aleksandrs Gavrilovs ${ }^{1}$, Janis Gerhards ${ }^{2}$, Anatolijs Mahnitko ${ }^{3}$, \\ ${ }^{1}$ Public Limited Company Sadales tikls, ${ }^{2-3}$ Riga Technical University
}

\begin{abstract}
Development of market relations in the power sector tightens the requirements for uninterrupted and qualitative power supply of customers. In the proposed work there is highlighted issue on determining the influence of the number of connected to the urban medium voltage distribution network elements (transmission lines, switchgear, transformer substations) and its impact on power supply reliability. Additionally, it is suggested the approach to the methodology of power supply company's potential damage calculation due to network equipment failure and electricity not supplied to consumers.
\end{abstract}

Keywords - distribution network, power supply, reliability, probability, secondary substation.

\section{INTRODUCTION}

Electrical equipment failure leads to the interruption of power supply, resulting in income decrease for power company. To minimize losses power supply should be restored as soon as possible. That's why it is necessary to take steps to identify the damaged item and putting it to work. If cable line in distribution network is damaged, then its repair may take several hours. Consequently, the scheme should ensure redundancy of each element in the distribution network. Then, by identifying and taking out of operation damaged element, consumers could be energized, and staff engages in recovery works.

In comparison with neighboring European countries unplanned System Average Interruption Duration Index (SAIDI) in Latvian $0.4 \mathrm{kV}-20 \mathrm{kV}$ network is one of the highest (Fig. 1) [1]. This is due to large proportion of bare wire overhead lines in forests, as well as weather conditions. A significant impact on Unplanned System Average Interruption Frequency Index (SAIFI) in Latvia has high proportion of forested areas, where historically large proportion of overhead $20 \mathrm{kV}$ lines is located. During the last 5 years the significant proportion of damage in average was due to nature and weather effects $(62 \%)$ and technical reasons (25\%), affected by network elements - technological and physical aging of materials.

In Latvian urban networks about a quarter of failures are caused by the actions of third parties (especially - during streets reconstruction). Therefore the probability of cable lines damage in cities is high. Any element failure in the distribution network with manual reserve switching leads to voltage disappearance on medium voltage transformer substations' busbars for the time of accident localization and switching on redundancy. That's why the problem of power supply reliability is very crucial.

With the development and reconstruction of existing medium voltage $(6 \mathrm{kV}-20 \mathrm{kV})$ distribution networks in Latvia increasingly arises the question: what is a reasonable number of customers connected to one feeder in terms of consequences of outages and influence on SAIFI? It is known that increase of serially connected elements in the network increases the probability of its failure [2, 3]. Therefore it is necessary to evaluate influence of number of transformer substations connected to one feeder on its no-failure operation's reliability. This paper deals with evaluation of power supply reliability in urban middle voltage distribution networks depending on number of serially connected elements.

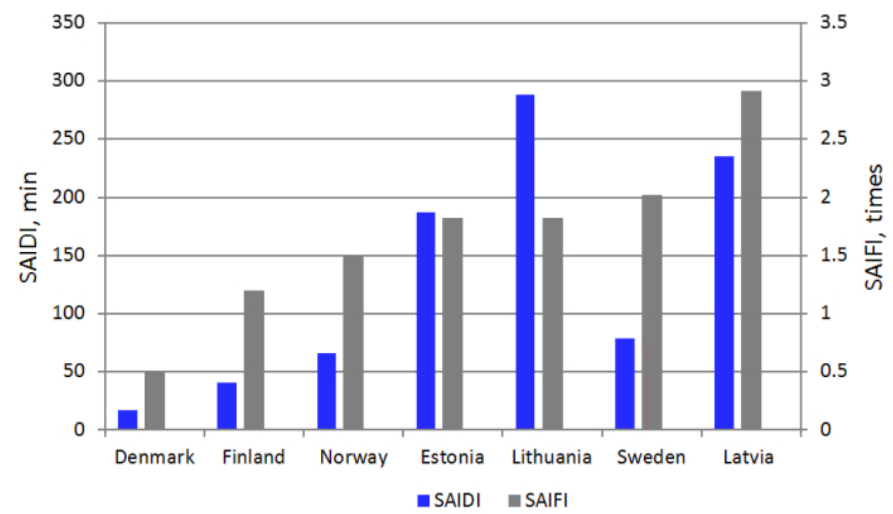

Fig. 1. Unplaned SAIDI and SAIFI in European countries (2013).

\section{SCHEMES OF URBAN DISTRIBUTION NETWORKS}

Basic schemes of urban distribution network $(6 \mathrm{kV}-20 \mathrm{kV})$ are loop and two- (or many) beam schemes: with double-sided power supply from two primary substations or one substation's different busbars (Fig. 2). Moreover those middle voltage schemes could be built as single-unit (without distribution points) or as multiunit (distribution network supply through distribution points).

There are normal open points between primary substations or distribution points in the middle voltage network of Latvia and it operates in radial mode (Fig. 2). Normal open points usually are placed taking into account such criteria as: minimal losses in the network, maximal power supply reliability, minimal average weighted voltage deviation on customer side from rated voltage. 
Creating conditions for uninterrupted power supply is an urgent task [4]. Key measures to improve reliability in $6 \mathrm{kV}-20 \mathrm{kV}$ networks are:

- improvement of the network structure;

- improving the reliability of network sections by replacing critical components to new components to reduce the risk of damage;

- introduction of automation and remote control switching devices to reduce recovery time after the accident in the network, as well as to predict emergencies;

- pre-designed logistics of emergency crews.

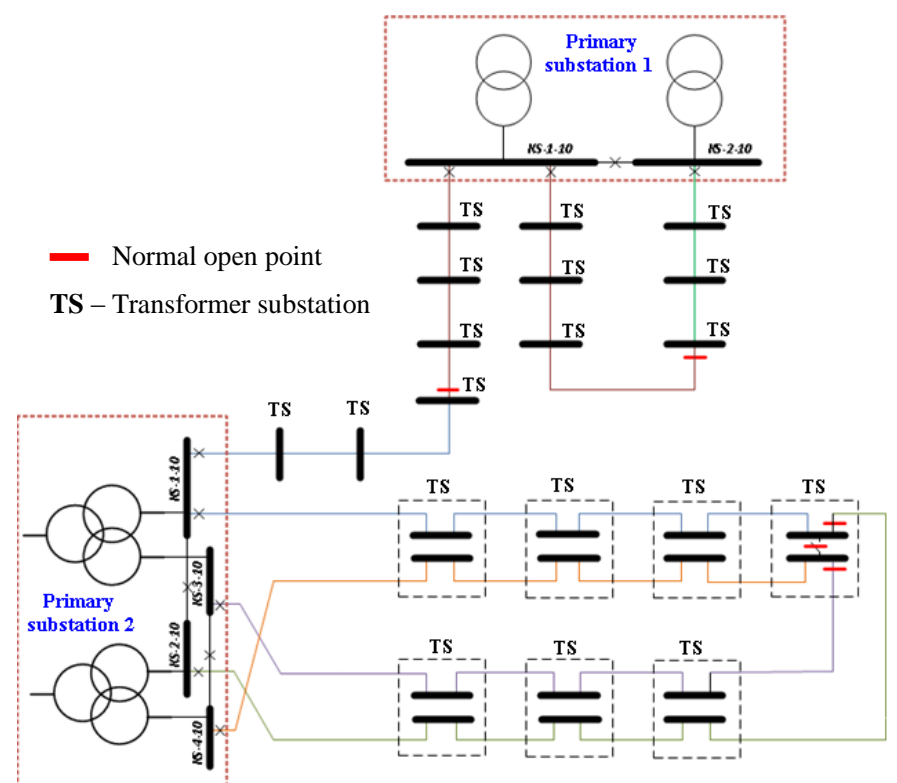

Fig. 2. Urban distribution network $(6 \mathrm{kV}-20 \mathrm{kV})$ structure without distribution points.

Naturally in real operating condition it is almost not possible to achieve uninterrupted operation of distribution networks. In accordance with Latvian distribution network operator AS Sadales tikls statistical data, the most common causes of damage in middle voltage distribution network in Latvia are: weather conditions, the action of third parties, aging equipment, operating errors, etc. (Fig. 3). In turn, the emergency outages lead to consumers power supply interruptions that bring damage both for clients of the power company (for example, stop the production process and spoilage), and for power company due to foregone income from electricity distribution.

Increase of serially connected elements in the network decrease power supply reliability [5-7]. Therefore to reduce the potential damage from the outages, the following factors with development and reconstruction of medium voltage distribution networks are taken into account:

- capacity of the feeder section with the smallest crosssection;

- number of clients connected till the open point;

- number of secondary substations connected to feeder;

- total annual consumption of all users connected to the feeder.

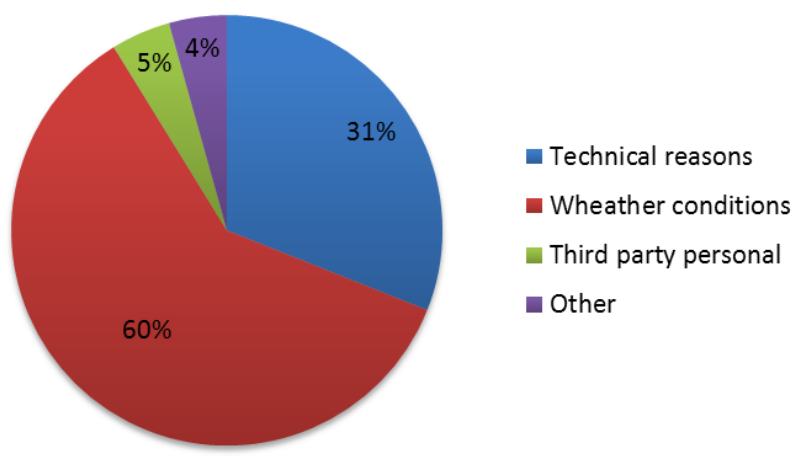

Fig. 3. Faults breakdown in middle voltage $(6 \mathrm{kV}-20 \mathrm{kV})$ network in Latvia (2013).

\section{POWER SUPPLY SYSTEM RELIABILITY INDICATORS}

The power supply system function is to provide all consumers with electricity of the required quality and quantity.

Reliability of the network section is determined by the reliability and parameters of its constituent elements (transformers, power lines, switching equipment, etc.). In case of particular element failure can occur (depending on the topology of network): network area failure, leading to disruption of consumers' power supply; complete power supply interruption; partial power supply interruption of individual customers; voltage deviation from acceptable standards.

One of way to evaluate power system reliability is the amount of electricity not supplied due to failures in the power system [8]. Expected amount of electricity not supplied for the consumer (node) $i$ corresponds to the product of the average load value $\bar{P}_{i}$ on the equivalent duration of downtime $\Theta_{i}$ during the time under consideration:

$$
W_{i}=\bar{P}_{i} \Theta_{i} .
$$

Then amount of electricity not supplied $W_{n s}$ is defined as the total amount of electricity not supplied to all $m$ users connected to the system:

$$
W_{n s}=\sum_{i=1}^{m} W_{i} .
$$

Equivalent duration of consumer $i$ downtime could be evaluated using the expression [9]:

$$
\Theta_{i}=\lambda_{i} T_{A i}+\xi v_{i} T_{R i},
$$

where $\lambda_{i}$ - failure rate, year ${ }^{-1}$;

$T_{A i}$ - recovery time of element $i, \mathrm{~h}$;

$\xi$ - factor reflecting less severity of consequences due to intentional disconnections compared to emergency failure (in practical calculations it could be assumed $\xi=0.33$ );

$v_{i}$ - intentional disconnection rate, year $^{-1}$,

$T_{R i}$ - service time of element $i$ after intentional

shutdown (duration of preventive maintenance), $\mathrm{h}$.

If elements of power system are connected serially, then failure of at least one of the elements leads to whole system 
failure, i.e. series structure able to work, if all its elements are functional [10]. Equivalent scheme (for reliability) of the system with series structure is shown on Fig. 4.

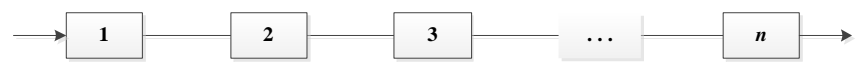

Fig. 4. Equivalent scheme of the system with series structure.

System failure rate and intentional disconnection rate of the system with $n$ elements series connection [7]:

$$
\begin{aligned}
& \lambda_{S}=\sum_{i=1}^{n} \lambda_{i}=\lambda_{1}+\lambda_{2}+\ldots+\lambda_{n}, \\
& v_{S}=\sum_{i=1}^{n} v_{i}=v_{1}+v_{2}+\ldots+v_{n} .
\end{aligned}
$$

Average recovery time of the system with series structure:

$$
T_{A}=\frac{\sum_{i=1}^{n} \lambda_{i} T_{A i}}{\lambda_{S}} .
$$

Average service time of the system after intentional shutdown:

$$
T_{R}=\frac{\sum_{i=1}^{n} v_{i} T_{R i}}{v_{S}} .
$$

Distribution system intentional shutdowns affect the reliability of power supply. On the one hand, during intentional disconnections preventive maintenance works are produced, for example, to improve the reliability, but on the other - the intentional shutdowns lower reliability of power supply, because they temporary create non-redundant circuits.

\section{EFFECT OF ELEMENTS NUMBER IN THE CIRCUIT ON THE DISTRIBUTION NETWORK RELIABILITY}

Failure of one element in the automated schemes triggers the relay protection and automation and failed element localization. In circuits with manual reserve switching on, liquidation time of the failure consequences depends on the work organization of operational staff. If there is no local staff on the substation, operations are performed by operational mobile team (OMT).

Dispatcher of power distribution company after receiving the information about power line disconnection (via remote signaling, message from consumers etc.) sends OMT to the substation. Finding the damaged section is made by test voltage switching on parts of the line, so the process is based on series OMT actions (search strategy). Search strategy provides consistent division of the line by load breakers in the direction from the power source. After damaged section finding and isolation, the next stage takes place - fault place location on a disjointed section and its repair. When recovery works are finished, the power supply scheme returns to normal mode.
Influence on reliability of elements number in distribution network with manual reserve switching is looked out on the example of a typical urban distribution $10 \mathrm{kV}$ circuit made by cable. $10 \mathrm{kV}$ line sockets of transformer substations $10 / 0.4 \mathrm{kV}$ (TS) are equipped with load breakers. In Fig. 5 loop is opened (open point) by the middle voltage load breaker in TS3 in the direction TS4.

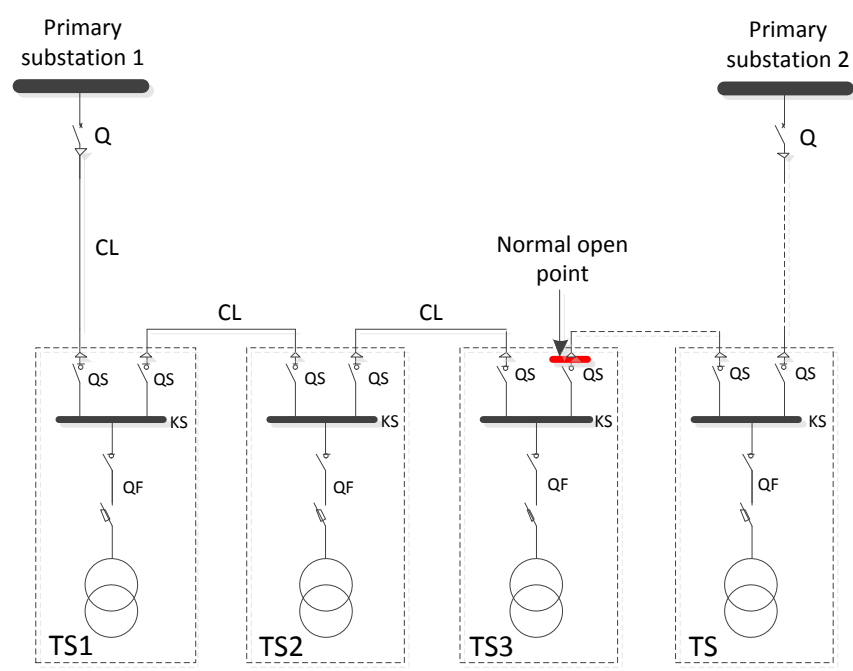

Fig. 5. Scheme of urban distribution network with manual reserve switching on.

In this scheme, the failure of any half-loop section leads to power supply interruption to all consumers up the open point until the arrival of OMT, finding and localization of the damaged section. In this case average power supply recovery time:

$$
\tau_{\text {rec }}=\tau_{\mathrm{s}}+\tau_{\mathrm{f}},
$$

where $\tau_{\mathrm{s}}$ - mean time from failure till damage finding process start;

$\tau_{\mathrm{f}}$ - average time of finding the damaged section.

The time required to repair the damaged element for distribution networks with double sided supply is not taken into account, because there are two power supplies in the scheme, and interruption time is equal to failure localization time - time of finding the damaged section and switching. However, repair time must be considered for urban medium voltage loop schemes in cases, when fault occurs on $6 \mathrm{kV}-$ $20 \mathrm{kV}$ busbars of the TS. If it is not possible to provide reserve power supply of consumers, connected to that TS, via low voltage network from the nearest TS, then damaged TS (and connected consumers) will remain without voltage for the time of fault localization and TS repair.

Time of damaged section searching, its localization and power supply recovery after localization involves in OMT driving during recovery process. The time required to move between two points $a$ and $b$ of the line could be evaluated as:

$$
\tau_{a-b}=\frac{l_{a-b}}{v},
$$

where $l_{a-b}$ - length of the section between points $a$ and $b$; $v$ - average OMT driving speed between points $a$ and $b$ 
In urban distribution networks cable lines between secondary substations are significantly shorter than overhead lines in rural areas. Therefore, damaged section searching time in urban distribution power systems can be set in averaged form depending on number of TS in the half-loop:

$$
\tau_{\text {mekl. }}=\frac{l_{\Sigma}}{n v}+n \tau^{\prime},
$$

where $l_{\Sigma}-$ the distance from the feeding substation up to open point;

$n$ - number of TS from the feeding substation up to open point;

$\tau^{\prime}$ - components of damaged section search time, determined as a result of statistical processing of historical data about networks damaging;

To evaluate the effect of TS number in the middle voltage half-loop on power supply reliability, reliability indices for consumers on the $10 \mathrm{kV}$ side of TS were calculated, varying the number of secondary substations to the open point from 1 to 15 (typical in urban medium voltage distribution networks of Latvia).

In the proposed urban $10 \mathrm{kV}$ network circuit breakers in primary substations have remote control, allowing dispatcher remotely commute them. Time components and average OMT driving speed were accepted based on analyses of average fault localization duration in urban $10 \mathrm{kV}$ network: $\tau_{\mathrm{s}}=0.4 \mathrm{~h} ; \tau^{\prime}=0.1 \mathrm{~h} ; v=25 \mathrm{~km} / \mathrm{h}$.

Reference reliability parameters of the distribution network equipment were taken from the data in Table $1[11,12]$.

TABLE 1

REFERENCE RELIABILITY PARAMETERS OF THE DISTRIBUTION NETWORK EQUIPMENT

\begin{tabular}{|c|c|c|c|c|}
\hline \multicolumn{2}{|c|}{ Type of equipment } & $\begin{array}{c}\text { Rated } \\
\text { voltage } \\
U_{\text {nom, }} \mathbf{k V}\end{array}$ & $\begin{array}{c}\text { Failure flow } \\
\text { parameter } \\
\lambda, \text { year }^{-1}\end{array}$ & $\begin{array}{l}\text { Recovery } \\
\text { time } T_{A}, \mathbf{h}\end{array}$ \\
\hline \multirow{2}{*}{$\begin{array}{l}\text { Circuit } \\
\text { breaker }\end{array}$} & vacuum & 10 & 0.004 & 8 \\
\hline & small oil volume & 10 & 0.009 & 10 \\
\hline \multicolumn{2}{|c|}{ Busbar (per one cell) } & $6-10$ & 0.01 & 4 \\
\hline \multicolumn{2}{|c|}{ Load breaker } & $6-10$ & 0.01 & 4 \\
\hline \multicolumn{2}{|c|}{ Cable line (1 km) } & $6-10$ & 0.05 & 5 \\
\hline
\end{tabular}

To calculate the reliability parameters of $10 \mathrm{kV}$ distribution network, the equivalent reliability scheme for consumers was prepared. As an example, the equivalent reliability scheme for consumers, connected to TS1, TS2 and TS3 till normal open point (from the primary substation 1 side) of urban distribution network (Fig. 5) is shown on Fig. 6. It includes such element reliability, as: circuit breaker on primary substation, cable line, load breakers and $10 \mathrm{kV}$ busbars on secondary substations. Reliability of $10 \mathrm{kV}$ primary substation's busbar and middle voltage couplings were not taken into account.

It was assumed during calculations that all allowed load of consumers connected to the half-loop is $P_{\sum}=5000 \mathrm{~kW}$. Then average half-loop load can be calculated as:

$$
\bar{P}=P_{\Sigma} T_{\max } / 8760
$$

where $T_{\max }-$ maximum consumption time, $\mathrm{h} /$ year.

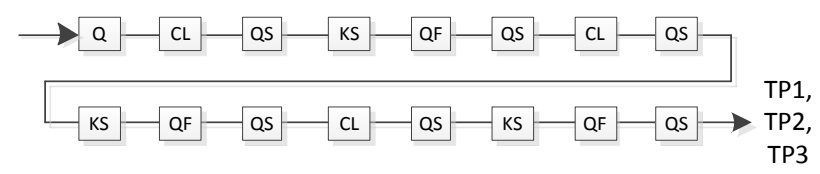

Fig. 6. Equivalent reliability scheme of urban $10 \mathrm{kV}$ distribution network with 3 TS series connection.

To evaluate real $T_{\max }$ in urban $10 \mathrm{kV}$ distribution networks, there were made calculations for several $10 \mathrm{kV}$ loops in Riga with different number of TPS, using the expression:

$$
T_{\max }=\frac{W_{c}}{\sum_{i}^{N} P_{i}},
$$

where $W_{c}$ - annual distributed amount of electricity, $\mathrm{kWh} /$ year;

$P_{i}$ - allowed load of consumer $i$, connected to the network, $\mathrm{kW}$;

$N$-total number of consumers in the network.

Only $10 \mathrm{kV}$ loops with mostly residential load were chosen for $T_{\max }$ calculation. Results of calculation for Riga distribution network in accordance with (12) are summarized in the Table 2. In accordance with real $T_{\max }$ values for residential load in Riga that were got in calculation, average value of $T_{\max }$ was determined $-T_{\max }=550 \mathrm{~h}$ (these value was used in future calculations of reliability). Such a low actual $T_{\max }$ value in Riga $10 \mathrm{kV}$ networks testifies to their underutilization and low power consumption (low use of allowed power) in the residential sector.

TABLE 2

RESUlts OF MAXIMUM CONSUMPTION TIME CALCULATION IN RIGA 10 KV NETWORK (RESIDENTIAL SECTOR)

\begin{tabular}{c|cccc}
\hline $\begin{array}{c}\text { Number of } \\
\text { TS }\end{array}$ & $\begin{array}{c}\text { Number of } \\
\text { customers }\end{array}$ & $\begin{array}{c}\boldsymbol{W}_{\boldsymbol{c}}, \\
\text { MWh/year }\end{array}$ & $\sum_{i}^{N} P_{i}, \mathrm{~kW}$ & $\boldsymbol{T}_{\text {max }}, \mathrm{h}$ \\
\hline 2 & 742 & 1452 & 2719 & 534 \\
3 & 605 & 1258 & 2166 & 581 \\
4 & 784 & 1765 & 2538 & 695 \\
4 & 2516 & 5635 & 9064 & 622 \\
4 & 1744 & 3297 & 5605 & 588 \\
5 & 1433 & 3026 & 5433 & 557 \\
5 & 1984 & 3576 & 6466 & 553 \\
5 & 1397 & 3273 & 5779 & 566 \\
6 & 1254 & 2577 & 4945 & 521 \\
7 & 2137 & 3165 & 6579 & 481 \\
10 & 3454 & 6504 & 14064 & 462 \\
11 & 2458 & 5320 & 10310 & 516 \\
\hline
\end{tabular}

Power distribution in Riga $10 \mathrm{kV}$ network ensure 27 primary substations by 597 feeders $(10 \mathrm{kV})$. The total length of all $10 \mathrm{kV}$ feeders in the city is $L=2345 \mathrm{~km}$. So the average feeder length from primary substation to open point (average $10 \mathrm{kV}$ network length connected to one circuit breaker in 
primary substation) in Riga is $l_{\mathrm{av}}=L / 597=3.9 \mathrm{~km}$. It should be kept in mind that there are also paired $10 \mathrm{kV}$ feeders in Riga network (for example, $10 \mathrm{kV}$ distribution points' feeding paired feeders), that's why the real average feeder length is shorter than $3.9 \mathrm{~km}$.

It was assumed in calculations that distance from primary substation to normal open point (last TS) is $l_{\Sigma}=3.9 \mathrm{~km}$.

Varying the number of series-connected TS from 1 to 15 (up to the normal open point), the equivalent duration of interruption $\Theta_{i}$ for all consumers, connected to all TS (for example, on Fig. 5 - for consumers at TS1, TS2 and TS3), and anticipated amount of electricity $W_{n s}$ not supplied to customers during the period 1 year were received. Accepting the price for power distribution $c=0.056 € / \mathrm{kWh}$, the anticipated damage $C$ for distribution company was evaluated due to power supply interruptions in urban middle voltage networks:

$$
\begin{gathered}
C=c W_{\Sigma}=c \sum_{j=1}^{m} \Theta_{j} \sum_{i=1}^{n} \bar{P}_{i}= \\
=c \sum_{j=1}^{m} \lambda_{j}\left(\tau_{i z m .}+\frac{l_{\sum}}{n v}+n \tau^{\prime}\right) \sum_{i=1}^{n} \frac{P_{i} T_{\max }}{8760},
\end{gathered}
$$

where $i=\overline{1, n}$ - number of consumers, connected to the network;

$j=\overline{1, m}$ - number of elements in the circuit, whose reliability is evaluated.

The results of calculations are shown in Table 3.

TABLE 3

RESULTS OF RELIABILITY PARAMETERS CALCULATIONS FOR URBAN 10 KV DISTRIBUTION NETWORK

\begin{tabular}{c|cccc}
\hline Number of TS & $\boldsymbol{\tau}_{\text {rec }}, \mathrm{h}$ & $\Theta_{i}, \mathrm{~h}$ & $\begin{array}{c}\boldsymbol{W}_{\boldsymbol{n}}, \\
\mathrm{kWh} / \text { year }\end{array}$ & $\begin{array}{c}\boldsymbol{C}, \\
€ / \text { year }\end{array}$ \\
\hline 1 & 0.66 & 0.170 & 53.3 & 2.99 \\
2 & 0.68 & 0.216 & 67.9 & 3.80 \\
3 & 0.75 & 0.285 & 89.5 & 5.01 \\
4 & 0.84 & 0.368 & 115.6 & 6.48 \\
5 & 0.93 & 0.465 & 145.9 & 8.17 \\
6 & 1.03 & 0.574 & 180.0 & 10.08 \\
7 & 1.12 & 0.695 & 218.1 & 12.21 \\
8 & 1.22 & 0.828 & 259.9 & 14.56 \\
9 & 1.32 & 0.974 & 305.6 & 17.11 \\
10 & 1.42 & 1.131 & 355.1 & 19.88 \\
11 & 1.51 & 1.301 & 408.3 & 22.87 \\
12 & 1.61 & 1.482 & 465.3 & 26.06 \\
13 & 1.71 & 1.676 & 526.2 & 29.46 \\
14 & 1.81 & 1.882 & 590.7 & 33.08 \\
15 & 1.91 & 2.100 & 659.1 & 36.91 \\
\hline
\end{tabular}

Assuming that failure rate for the power supply facilities during normal operation is virtually constant $(\lambda(t)=$ const $)$, probability of no-failure operation $P(t)$ (the probability that in a given time interval $(0, t)$ there will not be failure in the system) could be determined [9]:

$$
P(t)=e^{(-\lambda t)} .
$$

Using the expression (14) probability of the considered urban middle voltage network's no-failure operation for 1, 2, 3,4 and 5 years was estimated with different number of seriesconnected TS to the open point (at constant feeder length). The results of calculations are shown on Fig. $7-8$.

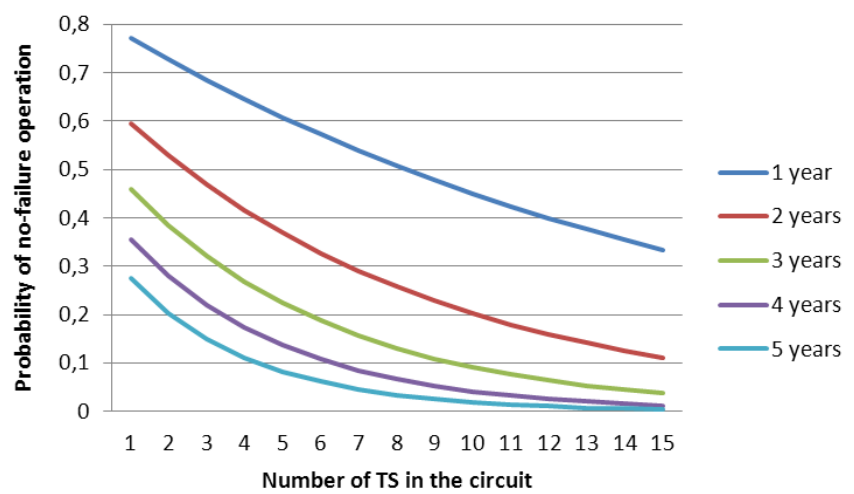

Fig. 7. Probability of $10 \mathrm{kV}$ urban network no-failure operation for $1-5$ years with different number of series-connected TS to normal open point.

Obtained on Fig. 7 results show that by increasing the number of series-connected elements in $10 \mathrm{kV}$ power supply half-loop, probability of no-failure operation decreases: increasing the number of connected TS from 1 to 15 , the probability of no-failure operation for a period of 1 year reduces by $50 \%$, but reliability for a period of 5 years - by $99 \%$ (probability of operation without failures during 5 years is almost 0$)$.

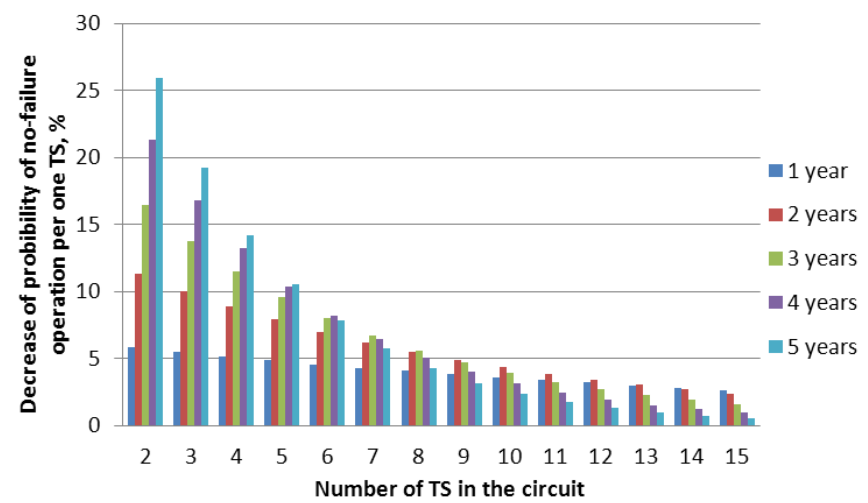

Fig. 8. Decrease of probability of no-failure operation (\%) for $1-5$ years in urban $10 \mathrm{kV}$ distribution network, increasing the number of TS to normal open point by 1 .

Fig. 8 shows how much (\%) reduces probability of nofailure operation of urban distribution $10 \mathrm{kV}$ network, increasing the number of series-connected TS in half-loop by 1 peace. Thus, with each subsequent series-connected TS, probability of $10 \mathrm{kV}$ distribution network no-failure operation reduces in average by from $4 \%$ for the period of one year, to $7 \%$ for the period of 5 years. At the same time, increasing the evaluation period ( 2 years and more) is characterized by a 
more dramatic effect of increasing the number of TS on the probability of circuit no-failure operation.

Fig. 9 shows how changes the probability of urban $10 \mathrm{kV}$ network no-failure operation within 5 years for schemes with different number $n$ of serially connected TS.

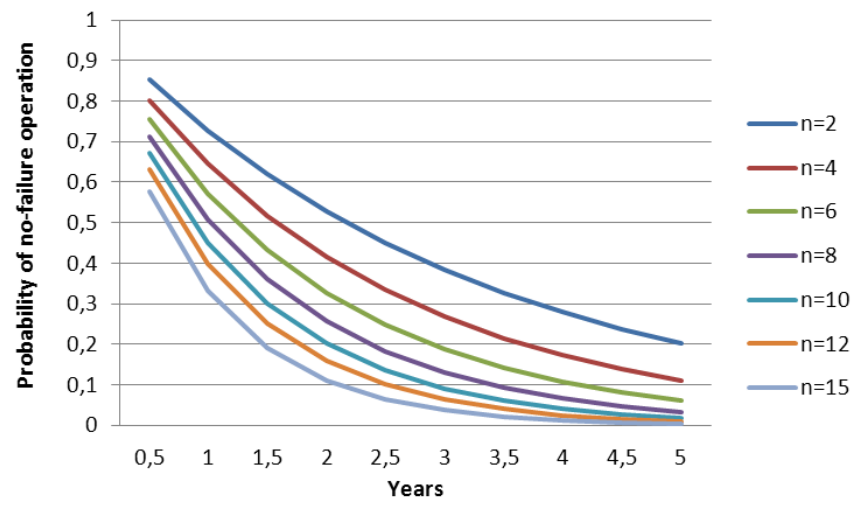

Fig. 9. Probability of $10 \mathrm{kV}$ urban network no-failure operation within 5 years with different number of series-connected TS to normal open point.

Calculation results on Fig. 9 show that by increasing the number of series-connected elements in the distribution network, probability of no-failure operation within 5 years decreases, wherein there is a greater relative reduction in circuits with more TS: from $45 \%$ at $n=2$, to $76 \%$ at $n=15$.

In urban $10 \mathrm{kV}$ network with loop structure all consumers power supply could be recovered in case of cable failure by damaged section localization and switching feeding from the base primary substation and other primary substation through the open point. Thus power supply interruption time equals to fault location and localization time, as it was shown in the expression (8).

If TP $10 \mathrm{kV}$ busbar is damaged, then after failure place localization power supply will be restored to all consumers, excepting those are connected to faulted TS. Sometimes it is possible to provide reserve power supply of those consumers by low voltage network from the nearest TS [13]. If it is not possible, then damaged TS (and connected consumers) will remain without voltage for the time of fault localization and TS repair:

$$
\tau_{\text {rec }}=\tau_{\mathrm{s}}+\tau_{\mathrm{f}}+\tau_{\text {rep }},
$$

where $\tau_{\text {rep }}$ - faulted section (equipment) repair time.

Thus equivalent downtime duration of consumers, connected to faulted TS, per year could be found using the expression:

$$
\Theta=\left(\tau_{i z m .}+\tau_{m e k l .}\right) \sum_{j=1}^{m} \lambda_{j}+\lambda_{k} T_{A k},
$$

where $\lambda_{k}-$ TS faulted element $k$ failure rate, year $^{-1}$;

$T_{A k}$ - TS faulted element $k$ recovery time, h.

It was evaluated how changes the equivalent failure time during the year of users, connected to $10 \mathrm{kV}$ loop, for two cases: when only failure localization time is observed, and when also repair time of damaged TS is taken into account in urban $10 \mathrm{kV}$ distribution network, depending on the number of TS and total cable line length up to normal open point.
Increase in the number of TS to the open point at constant cables total length, the equivalent downtime duration for consumers increases (Fig. 10-11). Results on Fig. 10 show that with increasing of total cables length increases the equivalent downtime duration. It is related with the highest probability of cable damage in cities and bigger distance between TS (more time needed to carry out reconnections in the network during fault localization).

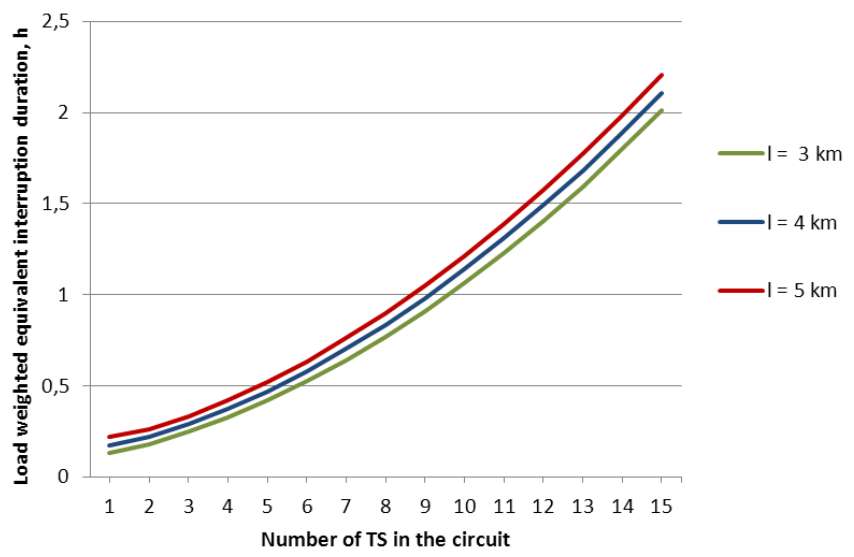

Fig. 10. Equivalent downtime duration during the year of consumers in the $10 \mathrm{kV}$ urban network with different number of series-connected TS to normal open point.

If TS $10 \mathrm{kV}$ busbar is damaged and power supply of connected consumers' could not be restored (via low voltage network), the equivalent annual downtime duration for those consumers increases with the number of TS in the loop (Fig. 11), but influence of total cable length up to normal open point on downtime duration is not so big $(\sim 2 \%$ increase per $1 \mathrm{~km})$. It is explained by higher TS repair time compared to the time required to localize the failure place.

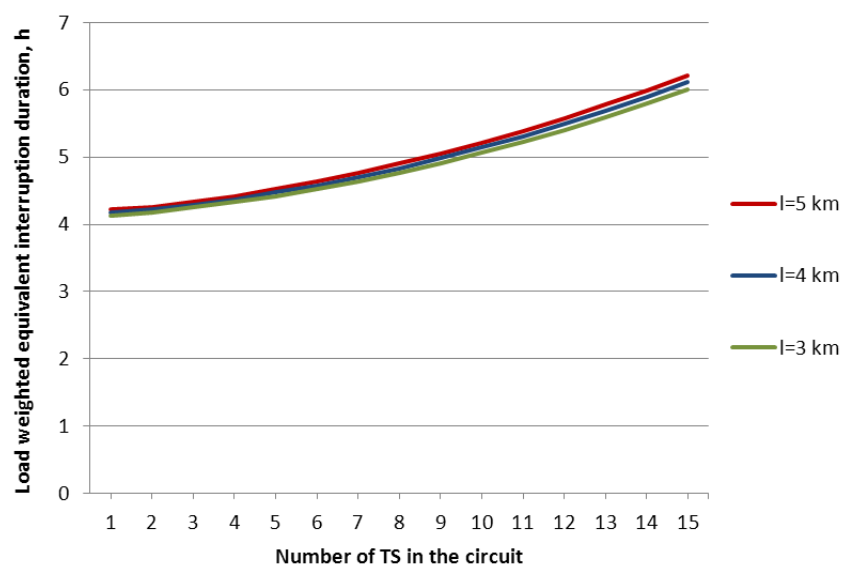

Fig. 11. Equivalent downtime duration during the year of consumers, connected to faulted TS in the $10 \mathrm{kV}$ urban network with different number of series-connected TS to normal open point, taking into account TS repair time.

Fig. 12 shows how changes the equivalent downtime duration per year of $10 \mathrm{kV}$ urban network, if total cables length up to normal point changes at constant number of TS. As it could be seen, increasing the total $10 \mathrm{kV}$ line length from $2 \mathrm{~km}$ to $5 \mathrm{~km}$ at constant TS number increase equivalent 
downtime duration per year by $20 \%$ (if the number of TS $n=10$ ), but if TS number is $n=5-$ then by $40 \%$. If failure is on $\mathrm{TS} 10 \mathrm{kV}$ busbar, then, considering repair time, feeder length increase from $2 \mathrm{~km}$ to $5 \mathrm{~km}$ causes a relatively smaller increase in equivalent downtime duration of customers, which are connected to the damaged TS - on average around $5 \%$ at TS amount $5-10$.

If it is possible to recovery power supply after fault localization, then equivalent downtime duration per year increases on average around by $50 \%$ (TS number increases from 5 to 7 ) or by $65 \%$ (TS number increases from 7 to 10) at constant $10 \mathrm{kV}$ feeder length. If TS $10 \mathrm{kV}$ busbur is damaged, then, considering repair time, the equivalent downtime duration's relative growth of consumers, connected to the damaged TS, is in average $6 \%-10 \%$, increasing the number of TS from 5 to 10 at a constant $10 \mathrm{kV}$ cables total length up to the normal open point.

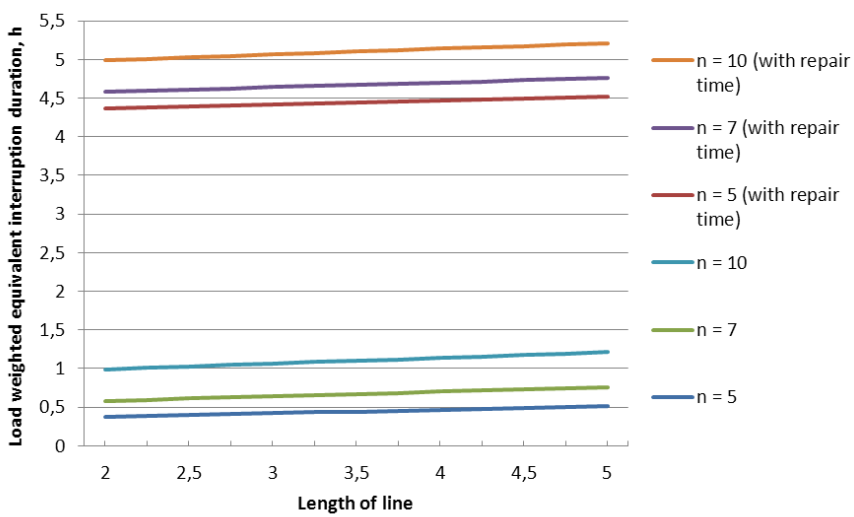

Fig. 12. Equivalent downtime duration during the year without and taking into account repair time of faulted TS $10 \mathrm{kV}$ side in the $10 \mathrm{kV}$ urban network with different number of series-connected up to normal open point TS.

\section{CONCLUSION}

1. The number of elements, connected to the urban $10 \mathrm{kV}$ distribution network, influences on power supply reliability.

2. The methodology for possible damage estimation of power distribution company from power supply emergency interruptions in the middle voltage urban network is proposed.

3. Statistical data accumulation about elements failure in the specific distribution network will increase accuracy of power supply reliability calculations.

\section{REFERENCES}

[1] CEER "CEER Benchmarking Report 5.1 on the Continuity of Electricity Supply." 2014, [Online]. Available: http://www.ceer.eu/portal/page/portal/ EER_HOME/EER_PUBLICATIONS/CEER_PAPERS/Electricity/Tab3/ C13-EQS-57-03_BR5.1_19-Dec-2013_updated-Feb-2014.pdf, Accessed on: Jul. 14, 2014

[2] T. J. Chen, H. Z. Cheng, and M. He, "Research on connection modes of urban middle voltage distribution networks." Power system technology, vol. 24 , no. 9 , pp. $35-38,2000$.

[3] R. Xing, A. Yao, "The analysis of loop operation of ring network." Zhejiang Electrical Power Supply, vol. 23, pp. 26-28, 2007.
[4] Y. B. Guk. Nadjezhnostj v jelektroenergetike. Leningrad: Jenergoatomizdat, 208 s., 1990 (in Russian).

[5] R. P. Gupta, R. K. Varma. "Technology development and implementation for power distribution automation." Water \& Energy International Journal, vol. 61, No. 4, pp. 40-47, 2004.

[6] M. A. Sabad. "Tehniko-jekonomicheskie obosnovanija avtomatizacii raspredelitelnyh setej." Jenergetik, vol. 9, pp. 23-28, 1998. (in Russian).

[7] V. E. Gurman. Teorija verojatnostey $i$ matematicheskaja statistika: uchebnoe posobie dlja vuzov. Moskva: Vishaja shkola, 491 s., 2001. (in Russian).

[8] Y. H. Xie, C. S. Wang, and S. Y. Ge. "Economy and reliability analysis of connection modes in urban distribution networks." Electric Power Automation Equipment, vol. 25, no. 7, pp. 12-17, 2005.

[9] V. A. Anishenko, V. I. Kolosova. Osnovi nadjezhnosti system jelektrosnabzhenija: uchebnoe posobie. Minsk: BNTU, 151 s., 2007. (in Russian).

[10] L.-H. Tsai. "Network reconfiguration to enhance reliability of electric distribution systems." Electric Power Systems Research, vol. 27, pp. 135-140, 1993. http://dx.doi.org/10.1016/0378-7796(93)90037-F

[11] B. J. Horoljskij, M. A. Taranov, D. V. Petrov. Tehniko-jekonomicheskie raschety raspredeliteljnyh jelektricheskih setej. Rostov-na-donu: Terra Print, 132 s., 2009. (in Russian).

[12] L. D. Fajbisovich. Spravochnik po proektirovaniju jelektricheskih setej. Moskva: NC JENAS, 350 s., 2006. (in Russian).

[13] S. Kazemi, M. Fotuhi-Firuzabad, M. Sanaye-Pasand and M. Lehtonen. "Impacts of loop restoration strategy on distribution system reliability," in Proceedings of the 2009 IEEE Bucharest PowerTech Conference, Bucharest, Romania, 28 June - 2 July 2009, pp. 1-8. http://dx.doi.org/10.1109/PTC.2009.5282107

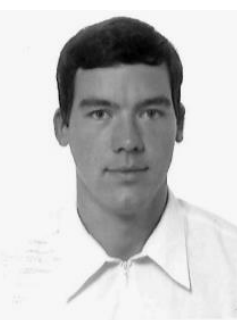

Aleksandrs Gavrilovs received B. sc., M. sc. and $\mathrm{Ph}$. D. degrees in electrical engineering from Faculty of Power and Electrical Engineering of Riga Technical University in 2005, 2007 and 2011 respectively.

He is currently an electrical engineer in a Network assets management function at Public Limited Company Sadales tikls.

His research field is power system development, planning and optimization.

Address: Smerla str. 1, Riga, LV-1160, Latvia;

Phone:+37126161738;

E-mail: a.gavrilovs@inbox.lv

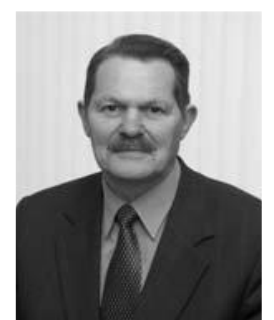

Janis Gerhards was born in Jelgava, Latvia on November 18, 1942. He graduated from the Riga Polytechnic Institute in 1966 and received Ph. D. in Power Engineering from Belorussian Polytechnic Institute in 1981. From 1973 he is working in Riga Technical University (RTU) as assistant, associate professor, professor, vice-president. Currently he is a professor of RTU Power and Electrical Engineering Faculty. His special field of interest includes power system optimization, reliability and planning.

Address: Azenes str. 12/1, LV-1048, Riga, Latvia;

Phone: +371 67089920

E-mail: gerhards@eef.rtu.lv

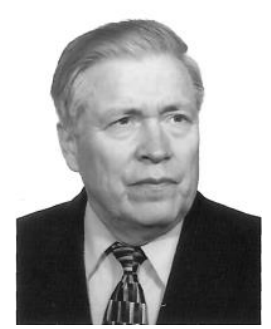

Anatolijs Mahnitko graduated from Mechanics and Mathematics Faculty of Kiev State University. In 1972 received scientific degree of technical sciences (Dr. sc. ing.) in the Riga Technical University. He has been working in RTU from 1972 as a senior lecturer, assistant, Associate Professor and Professor of Power Engineering Institute. His research interests include Electrical Power System mathematical simulation and optimization.

Address: Azenes str. 12/1, LV-1048, Riga, Latvia; Phone: +371 67089938

E-mail: mahno@eef.rtu.lv 